\title{
TAALGESINDHEDE EN DIE ONDERRIG VAN AFRIKAANS
}

\author{
Barbara Bosch ${ }^{1}$
}

In die onderrig aan en aanleer van Afrikaans deur nie-moedertaalsprekers behoort daar in 'n multi-kulturele omgewing met taalgesindhede rekening gehou te word: die taalaanleerder se gesindheid teenoor en stereotipiese sienswyses van die sprekers van die teikentaal en die teikentaal self beïnvloed die sukses van die verskillende stadia van die aanleerproses. Hierdie beinvloeding vind plaas omdat gesindhede motivering beïnloed en as sosio-affektiewe filter in die taalaanleerproses kan optree.

Die implikasies van heersende gesindhede teenoor Afrikaans vir die onderrig en aanleer van die taal in' $n$ multitalige situasie word indringend bespreek.

In the teaching of Afrikaans to and the acquisition of the language by non-mother tongue speakers in a multi-lingual environment, cognizance should be taken of prevailing attitudes: the attitudes of the learner towards the target language and his/her stereotypical perceptions of the target language and its speakers which influence the success of the language learning process in various stages. This influence takes place because attitudes affect motivation and can also act as a socio-affective filter in the language acquisition process.

The implications of existing attitudes towards Afrikaans for the teaching and acquisition of the language in a multi-lingual situation are discussed in depth.

\section{INLEIDING}

'n Sosiolinguistiese studie van taal gaan van die veronderstelling uit dat ' $n$ taal nie bestudeer kan word sonder om ag te slaan op die sprekers daarvan nie. Taalgebruikers (en by implikasie dus ook taalaanleerders) huldig bepaalde taalhoudings wat nie losgemaak kan word van die gemeenskap waarin die taalgebruiker hom/haar bevind nie (vgl. in die verband Cooper \& Fishman 1977, Owens \& Baker 1984, Harlech-Jones 1990, Roos 1990). Ook Webb (1985) ondersteun hierdie standpunt en stel dat ' $n$ persoon sy/haar houding teenoor ' $n$ groep mense op daardie groep se taal of dialek oordra. Hierdie gegewe lei daartoe dat duidelik waarneembare parallelle tussen gesindhede teenoor bepaalde sosiale groepe en gesindhede teenoor ' $n$ bepaalde taal bestaan.

Kulturele agtergrondsverskille het die ontstaan van ' $n$ komplekse stel houdings wat die aanleer van 'n nie-moedertaal kan beinvloed tot gevolg (Roos 1990: 25 - 26). Omdat geargumenteer kan word 
dat taal ' $n$ belangrike merker van kulturele identiteit is (Hauptfleisch 1983, Swanepoel in Webb (red.) 1992, Brown 1987), kan taalaanleer onder andere as 'n akkulturasieproses (Brown 1987: 128) wat deur taalhoudings beïnvloed word, beskou word.

In 'n situasie waar ' $n$ taal in 'n multitalige gemeenskap aan nie-moedertaalsprekers onderrig moet word, is die gesindhede wat die aanleerders en diegene gemoeid met die onderrig van die betrokke taal ten opsigte van die taal en sprekers van die teikentaal huldig, van kardinale belang in die aanleerproses van die betrokke taal. Die rede hiervoor is dat affektiewe faktore 'n geweldige groot invloed op die aanleer van nie-moedertale (hierna NMTe) het (Gardner 1988: 137, Roos 1990).

Gesindhede en die mate waartoe ' $n$ taalaanleerder empatie voel vir die sprekers van die teikentaal behoort tot die affektiewe domein. Naas gesindhede speel die aanleerder se selfbeeld, sy persoonlikheid, inhibisies en spanningsvlak egter ook ' $n$ rol t.o.v. die affektiewe. Om die aanleer van 'n NMT te benader slegs in die lig van kognitiewe faktore, sou dus kortsigtig wees, omdat dit nie rekening hou met die verskillende affektiewe faktore wat ' $n$ invloed uitoefen op die aanleer van ' $n$ NMT en die sterk emotiewe reaksies wat taal by die sprekers ${ }^{2}$ daarvan uitlok nie.

Navorsing wat postuleer dat taalaanleerders se gesindheid bepalend is vir die mate van sukses wat hulle in die aanleer van die NMT sal behaal, het die afgelope twee dekades toegeneem. Die algemene gesindheid van 'n taalaanleerder kan beskou word as die manier waarop hy/sy die betrokke taalsituasie sien, en in watter mate hy/sy positief of negatief ingestel is teenoor die aanleer van die NMT in die betrokke aanleerdersituasie, die NMT self en die sprekers daarvan (Roos 1990). Brown (1987: 51) is van mening dat negatiewe gesindhede teenoor die teikentaal self of teenoor die sprekers van die teikentaal die mate van sukses wat vanaf skoolgaande ouderdom met die aanleer van die teikentaal behaal word, beïnvloed.

'n Bewussyn van taalgesindhede ${ }^{3}$ behoort ' $n$ belangrike rol te speel in die verantwoordelike formulering van ' $n$ taalbeleid vir die onderwys. Lewis (1981: 262) is van mening dat enige taalbeleid, maar veral die taalbeleid van opvoedkundige instansies, rekening behoort te hou met die houdings van die betrokkenes en dat kennis van heersende houdings ook van wesentlike belang is in die suksesvolle implementering van die geformuleerde beleid.

\section{TAALGESINDHEDE}

Omrede die klem wat navorsers op die rol van gesindhede in die aanleer van moedertale plaas (Savignon 1976), is dit nodig dat die uiters komplekse begrip taalgesindhede onder die loep geneem word en nagegaan word hoe heersende taalgesindhede motivering in en die sukses van die taalaanleerproses beïnvloed.

\section{$2.1 \quad$ BEGRIPSOMSKRYWING}

Taalgesindhede van ' $n$ bepaalde individu is gekoppel aan affektiewe, emotiewe en kognitiewe faktore en hou onder andere verband met sosio-kulturele en sosio-politieke aangeleenthede. As 
gevolg van die linguistiese en historiese kompleksiteite van die Suid-Afrikaanse situasie, bestaan komplekse gesindhede en stereotipes in en teenoor die onderskeie Afrikaanse spraakgemeenskappe. Anders as opinies wat bewustelik gevorm word, is gesindhede gesetel in die onderbewuste (Roos 1990: 26). Volgens Krashen (1981: 21) moedig hierdie gesindheidsfaktore, wat ' $n$ "state of readiness rather than an observable response" is (Fasold 1984: 147) aanleerders aan om met sprekers van die teikentaal te kommunikeer en verkry die aanleerders die nodige blootstelling vir die suksesvolle aanleer van die teikentaal.

Taalgesindhede kan dus omskryf word as "any affective, cognitive or behavioral index of evaluative reactions towards different language varieties or their speakers" (Ryan et al 1982: 7). Hierdie taalgesindhede is ' $n$ diep-gewortelde stel faktore wat van kardinale belang is in die aanleer van NMTe (Fasold 1984: 148).

Hoewel daar in die navorsing veral gefokus word op die positiewe rol van gesindhede in die taalaanleerproses (Krashen 1981, Gardner \& Lambert 1972) kan gesindhede in 'n multitalige situasie die leerproses egter ook benadeel. Dit gebeur veral indien die taalaanleerder hom/haar "bedreig" voel deur die kultuur van die teikentaal.

Roos (1990: 26) beweer dat stereotipiese sienswyses van bepaalde groepe sprekers deel vorm van taalgesindhede "which could become obstacles in the way of language learning since it tends to categorize persons according to their accent and pronunciation, even without consciously associating them with certain reference groups." Resente navorsing (Dube 1992, Bosch \& De Klerk 1993) toon dat die stereotipiese persepsie wat NMT-sprekers van Afrikaans ten opsigte van Afrikaanssprekendes huldig, nie in alle opsigte positief is nie.

\subsection{GESINDHEID EN MOTIVERING}

Die gesindheid van aanleerders teenoor die teikentaal hang gewoonlik nou saam met die sosiale waardes en status van die betrokke taal en dié taal se sprekers in die samelewing: kulturele stereotipering gaan normaalweg hand aan hand met taalhoudings.

Gesindheidsfaktore kan die aanleerder motiveer om óf die teikentaal ten volle te wil bemeester óf om die teikentaal slegs met beperkte praktiese funksies voor oë aan te leer. Die begeerte om 'n teikentaal ten volle te bemeester, gaan volgens Krashen (1981: 22) gepaard met "the desire to be like valued members of the community that speak the second language".

Indien daar slegs belanggestel word in die aanleer van ' $n$ taal vir sekere praktiese redes, word slegs dié deel van die taal wat as gebruiksfunksioneel beskou word, aangeleer. Bepaalde aspekte (bv. ' $n$ kennis van die morfologie en die uitspraak van ' $n$ taal) wat ' $n$ geringer rol in die kommunikasieproses speel, word buite rekening gelaat. 


\subsection{GESINDHEID AS SOSIO-AFFEKTIEWE FILTER}

Die inhiberende invloed wat 'n negatiewe ingesteldheid op die leerproses, soos hierbo uiteengesit, kan uitoefen, word deur Dulay en Burt (1977) verklaar aan die hand van die sogenaamde "sosioaffektiewe filter". Só 'n filter raak effektief as die aanleerder om die een of ander rede op grond van sekere buitetalige faktore ' $n$ negatiewe gesindheid van die een of ander aard op die teikentaal of sprekers (daarvan) oordra.

Dulay en Burt (1977, aangehaal in Krashen 1981: 22) voer aan dat leerlinge met 'n sterk sosioaffektiewe filter minder van die beskikbare kennis oor ' $n$ NMT sal absorbeer, aangesien die sosioaffektiewe filter as't ware minder inligting tot die relevante deel van die aanleerder se brein "toelaat". 'n Gunstige aanleerdersituasie vereis dus dat die aanleerders gesindhede openbaar wat meewerk tot 'n lae sosio-affektiewe filter.

In die praktyk is dit die sosio-affektiewe filter wat bepaal watter van die variante van 'n taal die aanleerder uiteindelik sal internaliseer, watter dele van 'n teikentaal se sisteem eerste bemeester word, en waarom 'n aanleerder soms die leerproses staak voordat die teikentaal ten volle aangeleer is. ' $n$ Gemotiveerdheid om die teikentaal in sy geheel onder die knie te kry, dui op 'n laer sosio-affektiewe filter as wat die geval is by diegene wat die taal slegs aanleer met die oog op sekere gebruiksfunksies.

\subsection{GESINDHEDE IN 'N MULTITALIGE KONTEKS}

Wanneer ' $n$ taal aangeleer word, kan die nuut-verworwe tweetaligheid vir taalaanleerders sowel ' $n$ verruiming as 'n verskraling van hulle persoonlike kultuurerfenis tot gevolg hê. ${ }^{4}$ Wanneer aanleerders byvoorbeeld ervaar dat die kultuurkennis wat saam met 'n kennis van die NMT verwerf word, ' $n$ verlies van hulle eie kultuur en etniese identiteit meebring, kan hulle bedreig voel en kan die leerproses moontlik hierdeur gestrem word.

Die taalaanleerproses sal slegs suksesvol verloop as die aanleerder oor ' $n$ goeie selfbeeld ${ }^{5}$ beskik Aanleerders met 'n stewige selfbeeld vind nie dat hul eie kultuur noodwendig verlore gaan of aangetas word deur die kultuur waarvan die teikentaal ' $n$ identiteitsmerker is nie. Omdat sodanige aanleerders weerbaarder is teen die "skokeffek" wat volg op die interkulturele bestuiwing wat met die aanleer van ' $n$ NMT gepaard gaan, behoort ' $n$ aanleerder se selfbeeld, in die aanleerproses van NMTe in berekening gebring te word. Brown (1987: 100) beweer tereg: "(c)areful ... study of the role of personality in second language acquisition has already led to ... improved language teaching methods."

Die belang van ' $n$ aanleerder se "gesindheid teenoor die self" vir die aanleer van NMTe is tweeledig: groter selfvertroue lei tot 'n laer affektiewe filter, omdat die aanleerder nie so maklik bedreig voel nie. Verder bepaal die "gesindheid teenoor die self" die wyse waarop inhibisies die leerproses strem. Inhibisies lei tot ' $n$ hoë affektiewe filter, en hoe meer inhibisies ' $n$ persoon het, hoe onsuksesvoller sal die ontvangs- en reaksiestadium van die leerproses (vgl. paragraaf 4) wees. 
Nie net sal ' $n$ aanleerder wat onseker voel minder ontvanklik wees vir die inligting wat oor die NMT aan hom oorgedra word nie, hy/sy sal dit ook moeilik vind om daarop te reageer en aktief aan die leerproses te begin deelneem. In hierdie gevalle tree die affektiewe filter op om die inligting wat die self se waardesisteem wil relativeer, weg te weer (Brown 1987: 103).

Enige taalaanleerdersituasie is gebonde aan ' $n$ sekere emotiewe konteks, gevolglik kan die taalaanleerproses nie los gesien word van die affektiewe faktore wat ' $n$ invloed daarop uitoefen nie.

\section{GESINDHEDE TEENOOR AFRIKAANS}

Taalgebruikers gebruik taal om identiteit aan te dui en hoorders interpreteer hierdie talige leidrade; dus is taalhoudings belangrike aanduiders van die persepsies en stereotipiese reaksies van sprekers en hoorders.

Aangesien gesindhede (weens historiese ongelykhede) van taalgemeenskap tot taalgemeenskap verskil, bestaan daar, in die lig van die bogenoemde argumente, 'n dringende behoefte aan navorsing om die gesindhede teenoor Afrikaans (in die onderskeie taalgemeenskappe) vas te stel.

Sedert 1990 is die volgende taalgesindheidstudies (waarin gesindhede teenoor Afrikaans spesifiek nagevors is) onderneem:

Uit die navorsing van Booyse (1992) blyk dit dat leerlinge nie as sodanig negatief teenoor Afrikaans as skoolvak is nie, maar dat die onderrigwyse van die vak as negatief beleef word en dat hierdie negatiewe belewing aanleiding gee tot swak gemotiveerdheid ten opsigte van die vak, onderprestasie, lomp taalhantering en ' $n$ swak uitdrukkingsvermoë.

Dube (1992) bevind dat daar in die breë Soweto-gemeenskap die gesindheid teenoor Afrikaans negatief gestem word op grond van die "onderdrukkende aard" (Dube 1992: 122) van Afrikaans.

Hoewel Coetser (1993) tot die gevolgtrekking kom dat moedertaalsprekers in die Transkei oorwegend baie positief teenoor Afrikaans is, is die intrumentele waarde van Afrikaans in die Transkei beperk, omdat daar op openbare terrein slegs in 'n beperkte mate van Afrikaans gebruik gemaak word.

De Klerk en Bosch (1994) bevind dat daar in die Oos-Kaap 'n oorwegend positiewe gesindheid onder Afrikaans- en Xhosasprekendes teenoor Engels (en nie die onderskeie moedertale nie) bestaan; ' $n$ mindere mate van verdraagsaamheid teenoor Xhosa as teenoor Afrikaans word aan die dag gelế . 


\section{IMPLIKASIES VAN TAALGESINDHEDE VIR DIE ONDERRIG VAN} AFRIKAANS AAN NIE-MOEDERTAALSPREKERS

Die onderrig van Afrikaans as NMT in Suid-Afrikaanse skole het ' $n$ ver pad geloop sedert 1976, toe sterk negatiewe gesindhede teenoor Afrikaans (voortspruitend uit die verpligte gebruik van Afrikaans as onderrigmedium in sekere vakke) tot die opstand in Soweto-skole gelei het. Tans word 'n groter sensitiwiteit vir die bepalende invloed wat die gesindhede van NMT-sprekers op die aanleer van Afrikaans het, in 'n toenemende mate deur leerplanontwikkelaars aan die dag gelê. ${ }^{7}$

Dit is egter ook nodig dat diegene wat op voetsoolvlak gemoeid is met die onderrig van Afrikaans aan NMT-sprekers bewus moet wees van die rol wat gesindhede in die taalaanleerproses speel sowel as van die emotiewe prosesse wat ter sake is in die leerproses.

Volgens Krathwohl, Bloom en Masia (1964) is vyf belangrike stadia (wat deur gesindhede beïnvloed word) in enige opvoedkundige aanleerdersituasie ter sake en in die onderrig van Afrikaans behoort daar met hierdie stadia rekening gehou te word

In die ontvangstadium van die leerproses moet die aanleerder veral bereid wees om inligting te ontvang sonder om daarteen weerstand te bied, en om sy/haar aandag daaraan te wy. In die reaksiestadium moet die aanleerder nie net ontvanklik wees vir inligting nie, maar moet dit vir die aanleerder ook moontlik gemaak word om in ' $n$ meerdere of mindere mate te reageer op die aanleerdersituasie.

In die waarderingstadium van die leerproses, sal die aanleerder begin om sekere waardes te heg aan die situasie waarbinne die leerproses plaasvind, en die aard en gedrag van die persoon wat as onderwyser optree. Wanneer hierdie waardes geïnternaliseer word, neem dit die vorm aan van oortuigings en gesindhede. Vir die leerproses om ongehinderd voort te gaan, moet die aanleerder nie net bereid wees om met die gegewe aanleerdersituasie geassosieer te word nie, maar moet daar by die aanleerder ' $\mathrm{n}$ oortuiging bestaan dat Afrikaans aangeleer wil word.

Vervolgens vind daar by die taalaanleerder ' $n$ ordening van die waardesisteem plaas. Die waardes wat in die vorige stadium geïnternaliseer is, word tot ' $n$ hiërargiese sisteem wat voortaan gesindheidsbepalend sal optree, georden.

In die beskouingfase van die taalaanleerproses kan die aanleerders gekarakteriseer word aan die hand van hulle onderskeie waardesisteme. Hulle tree op volgens die gesindhede en idees wat tydens die leerproses by hulle posgevat het, en grond hulle wêreldbeskouing daarop.

Die bg. taksonomie het belangrike implikasies vir die aanleer van NMTe, aangesien dit veral uitsluitsel gee oor die wyse waarop gesindhede via die leerproses gevorm en waardes geïnternaliseer word. Hierdie gesindhede en waardebeskouings beïnvloed noodwendig die taalaanleerproses wat volg. Volgens Savignon (1976) is gesindheid die belangrikste faktor in die 
aanleer van ' $n$ tweede taal. Dit is dus baie belangrik dat persone gemoeid met die onderrig van Afrikaans aan NMT-sprekers, bewus moet wees van en sensitief moet wees vir gesindhede teenoor die teikentaal wat deur taalaanleerders geopenbaar word: taalaanleerders is as individue by die aanleerproses betrokke, dus is hul gesindhede belangrik.

Hierdie groeiende sensitiwiteit vir die sterk emosionele konteks waarbinne die onderrig van Afrikaans geskied, noodsaak verskuiwings in die taalbenadering wat vroeër in skole gegeld het: individue as taalgebruikers word binne wisselende sosiale verbande sentraal gestel. Daar bestaan 'n duidelike erkenning van die feit dat taalverwerwing (van die NMT) nie net met kognitiewe faktore in verband staan nie, maar ook ten sterkste deur affektiewe faktore bepaal word. Gevolglik moet daar in die onderrig van Afrikaans as NMT ' $n$ holistiese banadering (beide kognitief en affektief) tot die onderrig van Afrikaans geïmplimenteer te word. Daar behoort ook 'n al sterker klem gelê te word op die belangrikheid van die taalaanleerder se gevoelens, houdings en gesindhede (vgl. Roos (1990: 27) in dié verband)

Persone gemoeid met die onderrig van Afrikaans aan NMT-sprekers behoort, in ' $\mathrm{n}$ poging om taalaanleerders se volle potensiaal te bereik, die bron van 'n aanleerder se motivering te probeer vasstel sodat in bepaalde behoeftes voorsien kan word en sukses in die aanleerproses verseker kan word.

Die verskuiwing wat behoort plaas te vind, impliseer noodwendig ' $n$ wegbeweeg van die klem wat voorheen (in die onderrigproses) geplaas is op strukture in die taal en op taalprodukte, na die onderrig van taal as ' $n$ vorm van interaksie en kommunikasie binne 'n bepaalde sosiale konteks. Met die gesindhede wat by aanleerders teenoor die teikentaal bestaan, behoort te alle tye rekening gehou te word.

Om ' $n$ gunstige aanleerdersituasie te kweek vir die aanleer en onderrig van Afrikaans as NMT, waarin aandag geskenk word aan die houding van taalaanleerders en persone gemoeid met die onderrig van Afrikaans, behoort daar veral aandag geskenk te word aan die faktore wat sou kon meewerk tot die vorming van positiewer stereotipes en gesindhede as wat die genoemde studies aan die lig bring.

Wanneer ' $n$ persoon wat Afrikaans as MNT aanleer, gebuk gaan onder negatiewe stereotipes ${ }^{8}$ van Afrikaans, of van die sprekers van Afrikaans, sal daar slegs sprake wees van 'n taalaanleerproses wat gemik is op sekere beperkte gebruiksfunksies van Afrikaans in die Suid-Afrikaanse samelewing. Stereotipes (wat in baie gevalle op oorvereenvoudigings en onakkuraathede gegrond is) speel gevolglik ' $n$ baie belangrike rol in die suksesvolle aanleer van NMTe. Persone betrokke by die aanleer en onderrig van NMTe behoort inderdaad bewus te wees van die negatiewe gevolge van kulturele stereotipering vir die aanleer van NMTe, want "(l)anguage is seen as a means of expressing, together with a message, a personal and/or a group identity" (Schmied 1991: 185).

Op persone gemoeid met die onderrig van Afrikaans, rus ' $n$ verantwoordelikeid om vals stereotipes en mites omtrent die sprekers en kultuur van die teikentaal te ontbloot, om dit te probeer uitskakel en te probeer vervang met 'n realistiese beeld van die ander kultuur sodat 
daardie kultuur (en dus ook lede van daardie kultuur) gerespekteer sal word: Afrikaans is in 1996 nie sonder meer die taal van die onderdrukker nie, maar Afrikaans is ook die taal van bevryding.

Omdat negatiewe taalgesindhede dikwels die gevolg is van "false stereotyping or undue ethnocentrism" (Brown 1987: 127) is Brown (1987) van mening dat bestaande negatiewe gesindhede verander kan word deur persoonlike interkulturele kontak. Indien positiewe gesindhede deur leerkragte gekweek kan word en die aanleerders van Afrikaans bereid is om met Afrikaans en Afrikaanssprekendes geassosieer te word, sal taalaanleerders 'n hoër mate van taalvaardigheid bereik en uiteindelik beter presteer.

\section{TEN SLOTTE}

Dit het gebiedend noodsaaklik geword dat daar in die huidige sosio-politieke klimaat, aandag geskenk word aan aanleerders se gesindhede en stereotipiese persepsies van Afrikaans (die taal wat aangeleer word). Die ideale aanleerdersituasie kan slegs bewerkstellig word as leerkragte besef dat taalaanleerders se hele menswees by die leerproses betrek word, en dat aanleerders se houdings van die uiterste belang is. Deur dít te doen, is dit moontlik om 'n verantwoordelike en verantwoordbare standpunt t.o.v. die onderrig van Afrikaans in te neem.

Om te verhoed dat taalaanleerders die kultuurkennis wat saam met ' $n$ kennis van Afrikaans verwerf word, ervaar as ' $n$ verlies van hulle eie identiteit en kultuur, moet taalaanleerders van ' $n$ gesonde selfbeeld en positiewe opinie oor hulle eie etniese identiteit voorsien word. Die groter selfvertroue wat hieruit sal spruit, sal bydra tot 'n laer sosio-affektiewe filter, en sal hopelik verseker dat die taalaanleerder minder bedreig sal voel deur die kultuurimpak wat die aanleer van 'n NMT meebring.

In die finale analise rus die verantwoordelikheid vir die suksesvolle aanleer van Afrikaans enersyds op die taalaanleerder en andersyds op die skouers van die persoon wat in ' $n$ multi-talige omgewing gemoeid is met die onderrig van Afrikaans en sy/haar insig in heersende gesindhede teenoor Afrikaans en Afrikaanssprekendes. Deur op kreatiewe wyse Afrikaans in 'n gelukkige omgewing te onderrig, kan positiewe gesindhede uiteindelik gevestig word.

\section{EINDNOTAS}

1. Die bydrae van prof Vivian de Klerk tot ' $n$ navorsingsprojek (Taalhoudings in die OosKaap) waarvan die resultate direk tot hierdie artikel aanleiding gegee het, word met dank erken. Ook word die insette en insigte van Sonja Loots ('n honneursstudent in 1994) met dank erken.

2. Duidelik definieerbare taalhoudings bestaan by moedertaalsprekers, sowel as by niemoedertaalsprekers van ' $n$ bepaalde taal.

3. Die begrip taalgesindhede word volledig in paragraaf 3 bespreek. 
4. Vergelyk Lambert (1974) in die verband.

5. Coopersmith (aangehaal in Brown 1987: 101) definieer selfbeeld as volg: "By self-esteem we refer to the evaluation which the individual makes and customarily maintains with regard to himself; it expresses an attitude of approval or disapproval, and indicates the extent to which an individual believes himself to be capable, significant, successful and worthy."

6. Volgens Coetser (1994: 109) is $56,26 \%$ van die Oos-Kaapse bevolking Xhosasprekend, $30,14 \%$ Afrikaanssprekend en 12,43\% Engelssprekend.

7. Vergelyk die dokument Afrikaans in ons skole: Onderwysgidse i.s. Tussentydse vernıwings. Deel 1 wat in 1993 deur die (voormalige) Kaaplandse Onderwysdepartement gepubliseer is.

8. Anderson (1980: 154) beskryf stereotipes as "sets of beliefs about ... groups that the believer has little good reason for holding but that often serve to justify bigotry."

\section{BIBLIOGRAFIE}

ANDERSON, JR. 1980. Cognitive Psychology and its Implications. Londen: Freeman \& Co.

BOOYSE, C. 1992. Onderrigstrategieë ter verbetering van die houding van leerlinge teenoor Afrikaans as skoolvak. Ongepubliseerde MA. PU vir $\mathrm{CHO}$.

BOSCH, BARBARA EN DE KLERK, VIVIAN. 1993. Afrikaanssprekende Oos-Kapenaars: 'n bedreigde spesie? Tydskrif vir Geesteswetenskappe 33(4): 299 - 311.

BROWN, HD. 1987. Principles of Language Learning and Teaching. New Jersey: Prentice Hall.

COETSER, A. 1993. Afrikaans in die Transkei - 'n ondersoek na enkele sosiokulturele aspekte daarvan. Suid-Afrikaanse Tydskrif vir Taalkunde 11(4): 121 - 129.

--- 1994. 'n Voorlopige ondersoek na die taalopset in die Oos-Kaap - enkele sprekersubjektiwiteite. Suid-Afrikaanse Tydskrif vir Taalkunde 12(4): 108 - 117.

COOPER, R \& FISHMAN, J. 1977. A Study of Language Attitudes. In: J.A. Fishman, R.L. Cooper \& Conrad, A.W. 1977. The Spread of English. Rowley, Mass: Newbury House.

COOPERSMITH, STANLEY. 1967. The Antecedents of Self-Esteem. San Fransisco: W.H. Freeman \& Company. 
DE KLERK, VIVIAN EN BOSCH, BARBARA. 1994. Language attitudes in the Eastern Cape - a tri-lingual survey. Suid-Afrikaanse Tydskrif vir Taalkunde 11(4): 121 - 129.

DUBE, MMR. 1992. Language attitudes in Soweto - the place of indigenous languages. Ongepubliseerde MA. Soweto: Vista Universiteit.

DULAY, H \& BURT, M. 1977. Remarks on creativity in language acquisition. In: Burt, M., Dulay, H. \& Finnochiaro, M. (reds.). Viewpoints on English as a Second Language. New York: Regents. pp. $95-126$.

FASOLD, R. 1984. The Sociolinguistics of Society. Oxford: Basil Blackwell.

GARDNER, RC. 1988. Attitudes and motivation. Annual review of Applied Linguistics 9: 135 148.

GARDNER, ROBERT C \& LAMBERT, WALLACE E. 1972. Attitudes and Motivation in Second Language Teaching. Rowley, MA: Newbury House Publishers.

HARLECH-JONES, B. 1990. You Taught Me Language: The Implementation of English as a Medium of Instruction in Namibia. Kaapstad: Oxford University Press.

HAUPTFLEISCH, T. 1983. Language Loyalty in South Africa: Vol 4. Pretoria: RGN.

KRASHEN, SD. 1981. Second Language Acquisition and Second Language Learning. Oxford: Pergamon Institute of English.

KRATHWOHL, DAVID R, BLOOM, BENJAMIN EN MASIA, BERTRAM B. 1964. Taxonomy of Educational Objectives. Handbook H: Affective Domain. New York: David McKay Company.

LAMBERT, WE. 1974. Culture and language as factors in learning and education. In: Aboud, F.E. \& Meade, R.D. (reds). The fifth western symposium on learning: Cultural factors in learning and education. Bellingham, WA: Western Washington State College. pp. 91 122.

OWENS, THOMPSON W \& BAKER, PAUL M. 1984. Linguistic insecurity in Winnipeg: validation of a Canadian index of linguistic insecurity. Language in Society 13(3): 337 350 .

ROOS, RIANA. 1990. Language attitudes in the second language situation. Per Linguam 6(2): $25-30$.

RYAN, E, GILES, H \& SEBASTIAN, R. 1982. Attitudes towards Language Variation. Londen: Edward Arnold. 
SAVIGNON, S. 1976. On the other side of the desk: a look at teacher attitude and motivation in second language learning. Canadian Modern Language Review 32: 295 - 302.

SCHMIED, JOSEF. 1991. English in Africa. Londen: Longman.

SWANEPOEL, PIET. 1992. Taal, emosies en die toekoms van Afrikaans. In: Webb, V.N. 1992. Afrikaans ná Apartheid. Pretoria: J.L. van Schaik.

WEBB, VN. 1985. Taalnorme en Afrikaans. 'n Geval van twyfel en vertwyfeling? In: Botha, R.P. and Sinclair, M. (reds.). 1985. Norme vir Taalgebruik. Spil Plus 10: 42 - 56.

--- (red.). 1992. Afrikaans ná Apartheid. Pretoria: J.L. van Schaik. 